\title{
Changing Views: The Chaotic Postmodern and the Old Strategies of Realism in the American Novel $^{1}$
}

\author{
Francisco Collado Rodríguez \\ Universidad de Zaragoza
}

At this very moment western civilization is in the discursive process of consolidating the age of the post-human. Our bodies are now understood as ephemeral beings subject to a process of continual physical change, their basic function seems to be nothing more than playing the role of the material ground where data is always provisionally contained. From our DNA codes to the functioning of the human brain everything is data, and data is the only entity that will exist when we "leave the meat behind," as cyberpunk writer William Gibson put it. In part thanks to cybernetics, human beings have been forced to face the instability of their condition (Hayles ch $2 \& 3$ ), but along the twentieth century scientific premises have frequently run along parallel paths to those trodden by philosophers and cultural critics. The instability of the self has also been a favourite argument among intellectual circles for the last few decades and has been frequently related to the main way in which people transmit data: language. The lacanian human being is an unstable subject trapped by linguistic metaphoricity, and so is the Derridean. When the scientific, the poststructuralist, and the artistic meet at the cross-roads of the postmodern, the ideological deed has already been accomplished: the self escapes, no previous value can hold its ground, and the moment comes for the formulation of a new reality.

Nowadays, the history of fiction obviously calls for the necessity to cope with the postmodern visions of reality. Correspondingly, writers have revised their technical strategies so as to fit them within contemporary beliefs about life. What follows is a short attempt to recognize and value the predominance of some technical strategies that accompanied postmodern fiction in its revaluation of realism. The condition of instability, the emphasis on fragmentation, or the disruption of traditional genres were not issues that could be easily matched with realism. How could writers relate the postmodern to the old realist structures? I will try to answer this question with the help of scientific and literary history. First I will briefly comment on some facts connected to the beginnings of the English novel, to the impact of social issues in the strategies used by those early novelists, and to the role played by scientific discourse in modifying the bourgeois understanding of reality at the time. Later, I will deal with some notions pertaining Darwinism and entropy, and with the literary "post-realist" result that was baptised as Naturalism. Finally I will pay a closer attention to the twentieth century and to the different revolutionary scientific theories that helped in the formation of the modernist and the postmodernist ethos, and to the latter's narrative game with the realist.

\footnotetext{
${ }^{1}$ The research carried out for the writing of this paper has been financed by the Spanish Ministry of Education (DGICYT: Programa Sectorial de Promoción Gral. del Conocimiento 1995-98, PB97-1022).
} 
For some years now, the critical conviction has been that the English novel is in a sense a literary product of Anglo-Saxon bourgeois mentality (Daiches; Watson). The celebration of aristocratic poetry and poetic forms in the English Golden Age finally had to give way to a new form of entertainment more in accordance with the new powerful people who, from the second half of the seventeenth century, constituted the reading public: the rich middle and upper classes. Their pragmatic views, their interest in social progress, and their necessity to be saved by means of their own merits gradually crystallised in a revival of the old classic motto of delectare et prodesse: to learn while at the same time receiving literary pleasure became a maxim among the reading public towards which the first English novelists were obliged. No wonder then that the last half of the seventeenth century and the first decades of the following one became the appropriate setting for the new type of narrative literature represented by poets such as the encyclopaedic Milton or the satirists Dryden or Pope: the narrative, to tell a story, was rediscovered as a befitting way both to entertain readers while also teaching them a moral. There were also at this time some astute authors that decided to fully liberate the narrative from the formal constraints of poetry and decided to write their stories in prose form. In this liberatory mood the modern English novel was born. Social conditions favoured that it was born amidst a sustained effort on the part of writers to produce in their readers the impression of credibility and objectivity: the world was out there to be described but equally important was to convince the public that what was being reported was totally credible or, even better, that those reported events had actually happened. Some of the first examples that characterise the early stages of the English novel show an outstanding artistry in producing credibility, Daniel Defoe's A Journal of the Plague Year being one of the most remarkable instances. In those years there is a proliferation of narrators who have also been participants or protagonists of the stories they narrate, and who offer the best proof of the story's veracity: their own role in it. Other realist strategies are soon applied with similar intentions, for instance, Richardson's use of apparently real letters to convince readers of the veracity of his reports.

The emphasis that this period puts on the paradoxical credibility of fiction runs parallel to the coming of the enlightened project of the Modernity, a project that is also deeply rooted in new scientific discoveries that resulted in a new interpretation of the laws of motion and in the synthesis of the laws of bodily attractions promulgated by the most eminent scientist of the time: Sir Isaac Newton, the father of classic physics. Newton's ideas meant the end of the prevalence of ancient Greek theories about the way the universe exists, and also the beginning of an optimistic belief in the human capacity to know and understand the world (Nadeau). The pertinacity of his celebrated Law of Gravitation acquired the category of universal and his theories, basically promulgated in his Principia, became a firm support for the bourgeois belief in their own competence to understand and faithfully describe the world.

By the beginning of the nineteenth century, when Napoleon ruled over half of Europe, one of his scientists, Pierre-Simon Laplace, had extended this optimistic Newtonian understanding of physics and happily proclaimed that a demon or hypothetical figure with an extraordinary mathematical capacity that knew the initial conditions of a system (and let us think of the universe as the biggest existing system), would be able to predict its evolution for eternity (Hayles 89). In other words, now that scientists believed that the universe was ruled in accordance to a 
set of definite and universal laws, it was clear that the human being was on his right path to know it all.

However, the impact and subsequent development of Newtonian theories cannot be considered only with regards to the social project of the Enlightenment. The development of scientific beliefs is also in correspondence with a certain departure from previous realist strategies in the history of the English novel. It does not come as a surprise, therefore, the abundant use of thirdperson narrators that exists in the times of "classic realism," in the nineteenth-century. Authors like Charles Dickens, William Thackeray, George Eliot, or Anthony Trollope offer in their fiction many examples of this device. This type of non-participant narrator is also characterised by another peculiar attribute: it is usually omniscient, a sort of god or, in a sense, it seems to be a literary correlate of Laplace's Demon.

The nineteenth century also brings questions about the gradual shift that, starting in the previous optimism about the capacity of the human being to know the world-the Enlightenment Project—carried western mentality into much more negative views about life and reality. Obviously there are many and different reasons that help us to explain this ideological shift from the type of novel represented by Richardson, Sterne, or Defoe into the more bleaker views of Dickens or Balzac. And here, once again, scientific discourse contributes, together with other social and anthropological reasons, to the new pessimistic mood. Nowadays it is a well-known fact that one of the main scientific ingredients that added into the increasing negative views already apparent as the nineteenth century advanced were Charles Darwin's ideas. His work The Origin of Species and his idea of the survival of the fittest meant a total reinterpretation of physical reality: from being something that humans will utterly control in the future (Laplace), life has now changed into a more unstable, impredictable entity that is subject to many variables. These variables may bring about modifications that become ultimately responsible for incredible changes in the living species of this planet. In a sense, we may now affirm that Newtonian stability disappears in Darwinian theory for the benefit of a new interpretation of the world more in accordance with our own contemporary theories in thermodynamics (White 104-105): Darwin hints at what contemporary scientist Ilya Prigogine qualifies as "far-fromequilibrium conditions" that may produce transformations from apparent disorder, from thermal chaos, into order, or vice versa (Prigogine \& Stengers ).

However, there is another scientific key-stone in the nineteenth century that also helps us to understand the ideological shift that, within literary grounds, means the entrance into that pessimistic post-realism labeled as "Naturalism." I am obviously referring to the Second Law of Thermodynamics or Law of Entropy, promulgated by Rudolph Julius E. Clausius in 1865. The law of Entropy, with its implication that the Universe (the ultimate close system we know about) is cooling off or running shorter of its available energy, represents another heavy blow for that scientific and bourgeois confidence in the human powers traditionally expressed within the context of Newtonian mechanist laws. The cultural influence of the Second Law of Thermodynamics is already felt very deeply by the turn of the century, with Henry Adams's celebrated work The Education of Henry Adams as one of the best intellectual examples of the grip the pessimistic law has on American letters. The strategies of social denounce carried out by the naturalist muckrakers perfectly fit in this bleaker interpretation of a Universe that here 
appears as a reality running out of force, justice, and creativity. The depiction of the city as a monster or of cheap tenement housing as a source of conflicting and dissipative gossiping are strategies that readers can easily trace in Theodore Dreiser's or Stephen Crane's works. The latter clearly anticipates in Maggie: A Girl of the Streets the notion of entropy in information flow that, some six or seven decades later, will characterise a very interesting part of American postmodern fiction.

However, the beginning of the twentieth century meant many more heavy blows to the mechanist self-confidence in understanding and controlling the world. The story of what Modernism meant has been narrated so often that probably a few indications are sufficient in order to establish the links existing at the time between scientific discourse and narrative strategies. Modernism can be epitomized by the emphasis on the inner gaze or the necessity of individual introspection to know oneself and therefore to know the world. The spreading of new studies in psychology, the foundations of psychoanalysis and a paradoxical acceptance and rejection of science and the new technologies were all important elements in the transformation, at the beginning of the century, of both European and American culture. Somehow the result was the final rejection of the bourgeois project of the Modernity and the necessity to find a metaphysical way-out, something that was accomplished by means of the creation of a new metanarrative: the discourse of myth, the belief in a set of mental universal patterns that led human beings towards the liberating recognition of the meaning of life (Manganaro). Psychoanalysis, especially represented by the theories of Sigmund Freud and Carl G. Jung, and modern anthropological studies_-Sir James G. Frazer and his influential study The Golden Bough —eventually meant a peculiar ideological shift: the validity of universal physical laws (mechanist philosophy and classic physics) was being replaced by a new belief in the validity of universal psychic patterns. That is to say, Modernism, even in its rejection of the masternarrative of the Enlightenment, had created a new master-narrative still rooted in the belief of universal norms. The works of T.S. Eliot, Virginia Woolf or William Faulkner offer very clear proof of that in the grounds of both British and American literature.

Some years after the high peak of Modernism came to an end readers could still approach notions such as the ones defended by anthropologist Joseph Campbell who in his work The Hero With a Thousand Faces traced and believed in the existence of a pattern that he denominated "the quest of the hero of the monomyth." According to Campbell, who mostly followed Jungian theories, any human being can follow a path of introspection towards the discovery of the meaning of life, a psychic path that has been abundantly exemplified in many religious rituals, folklore, and even in popular literature.

Modernism, in this sense, could have become a type of culture confident in the powers of the individual mind. In this way it could have solved the anguishing metaphysical problems that the new century had brought about. In effect, some authors talked about states of superior knowledge: James Joyce wrote about "epiphanies," Virginia Woolf about "visions," while Carl Jung became obsessed with the power of the circle or mandala as the psychic way to approach what he believed to be an "immediate experience" of the meaning of life. But metaphysical hope was not firmly rooted at the time. One of the main issues of the time, as Brian McHale contended some years ago, was epistemology: how to know the world and how to communi- 
cate with the others became two of the most problematic issues of modernist literature and language started to be considered by some as a very difficult tool to tackle: for the modernist artist it was not sufficient to have a vision or an epiphany or to experience a mandala in your dreams, then you had to translate that untranslatable experience into language. To complicate things further, in the grounds of science the world was beginning to be understood as something more complex than previously thought; the Universe was not simply ruled by mechanist forces but also by the continuum space-time and by an infinite number of sub-atomic collisions that took place in the microscopic world. New theories, mainly sprouting from nineteenthcentury research, eventually resulted in Einstein's formulation of his famous theory of relativity and in the development of quantum mechanics, the latter being a clear predecessor of the Derridean deconstruction of binary modes of thinking. Old notions about the structure of the atom together with traditional humanist beliefs in the categories of essence, substance, and quantity, and in the absolute existence of time and space, became gradually replaced by new theories that escaped the range of human sensorial perception (Davies \& Gribbin 4-23), in this way inflicting a new blow to the pragmatic understanding of life that had characterized the project of Modernity.

It is now common understanding that Albert Einstein was not only the intellectual father of the theory of relativity, whose postulates were soon to be transmuted into modernist literary works (Wilson). To a certain extent he was also responsible for the development of quantum - mechanics: centering his analysis on the photoelectric effect, Einstein proved that light energy does not simply manifest in waves—as Thomas Young had pointed out already in the nineteenth century-but also in spatial units denominated quanta. What it means in lay terms is that the electron manifests itself as both wave and particle at the same time: or as physicists say, the electron behaves in a schizophrenic way. As scientist Paul Davis affirms (165), common sense and intuition became the first victims of Einstein's formulae. Quantum analysis soon led some scientists to doubt even the possibility of ever reaching any accurate knowledge of life, in this way adding to the epistemological difficulties of modernist times.

Following the development of quantum mechanics, Werner Heisenberg formulated his famous "uncertainty principle" that affirms that pairs of quantities - that is to say, the position and momentum of the electron—are incompatible for scientific measurement, meaning by this that they cannot be simultaneously measured: scientists become uncertain in the face of the quantum atom because they can only choose which quantity to measure first, but the more precisely one quantity is measured the more imprecise data will be obtained about the other quantity. This paradox, that clearly ruled out the validity of Aristotelian norms of categorical thinking (Collado), was inextricably united to another epistemological problem: scientists and their instruments inevitably always interfere, by means of the very act of observation, in the behavior of the quantum particle (Davies \& Gribbin 201-06). The popularity of this Heisenbergian notion has been such that even in contemporary fiction and literary criticism writers still try to confuse pragmatic readers with explanations of this disturbing scientific principle (Kraft 132-38).

According to Heisenberg's principle accurate measurement, at least on the subatomic level, is virtually impossible for the human being. This premise, when put together with Einstein's 
emphasis on the relativity of all knowledge (but for the speed of light), including macro-reality, clearly results in more uncertainty to a cultural world already anguished by the effects of the First World War. Needless to say, the impact of relativity and quantum theories and their rejection of some traditional Newtonian beliefs brought about the first scientific revolution of our century. Readers interested in American fiction can easily find literary correlates of the emphasis science put on relativity. Different perspectives and techniques amalgamate in keystones of the American modernist novel, such as Dos Passos's USA or Faulkner's The Sound and the Fury: the interpretation of life is now relative to the source of knowledge, to the mind that focalizes on the world and to the voice that reports on it. An omniscient narrator mixes with a peculiar Camera Eye in Dos Passos's trilogy, or Benjy's understanding of the world radically differs from that of his brother Quentin's in Faulkner's novel. Also highly noticeable is the abundant use in modernist fiction of the technique of free indirect style: by means of this technical strategy the ontological limits between the narrative voice and the private focalization of the characters are frequently blurred, and relativity also confirms its important ideological role in the grounds of the narrative.

Within the complex grounds of modernism, however, scientific relativity seems to enter into conflict with that emphasis on universality that I referred to when dealing with modernist introspection and the creation of a master-narrative of myth. In the first decades of the twentieth century forms of universality were not restricted to the grounds of creative literature, of psychoanalysis, or of anthropology: Ferdinand de Saussure also tried to formulate a universal theory for the understanding of language, the Russian formalists also started their quest to find out the few rules that govern language, and still scientists could not forget that Newtonian physics offers valid procedures to interpret many aspects of life. From the 1930s onwards, some thinkers such as Jacques Lacan, started to develop more totalizing theories about the human being that critics used, in later years, to oppose that typical emphasis on totalization and absolute knowledge, an emphasis that has frequently characterized western culture. Gradually, as we moved into the territory of the postmodern, language was understood as something paradoxical, that human beings tried to use now in order to reject traditional categorical thinking and to erase all confidence in clear limits, and in the concepts of human essence and stability: but there it was, in modernist linguistics there had been an attempt to present language as something stable, perfectly controlled by a series of rules studied by the linguists... And language trapped us, in Lacanian or in Borgesian, or even in Eliotean terms: Nominalism had also reappeared in cultural modernism, the use of language constituting the root of the epistemological difficulties it brought about. There was no way to escape language, and in the realm of creative narrative language conducted us only to more language, and there stand T.S. Eliot, James Joyce, or Flann O'Brien to suggest that in Modernism the circle of myth is not the only one that traps us: fiction escapes into meta-fiction, life starts to be interpreted as a textual web and, as a result, the human being acquires the condition of a mere symbolic animal.

After the Second World War, in the intellectual climate reason and mythic faith held their ground together and, as happened in the realm of science, post-war American culture was also becoming immersed in the prevalence of paradox, one of the most effective marks of the postmodern condition, and chaos was preparing its entrance into the world of letters. Classic handbooks on the post-war American novel frequently inform us that this period brought about a 
very interesting amalgamation of writers who created works in the spirit of the grotesque and experimental and novelists who went back to old realist strategies that were however mediated by the use of powerful symbols, a strategy clearly inherited from Modernism. Anglo-Saxon critics were also surprised by a wave of excellent Jewish writers who soon started to be praised in the American literary market while at the same time being labeled as "novelists of manners" and attributed the qualification of "realist writers." In the post-war period, however, the limits of realism were not the ones that had existed in the nineteenth century: to reproduce the external world in mimetic terms was something that now many thought to be simply a naive bourgeois dream. Classic realism had been replaced by modernist psychological realism, and already in the sixties many intellectuals were accepting the belief that human beings are trapped in semiotic codes and that knowledge is always something relative to the frame of reference and the instruments used by the knowing subject. As I argued earlier in this paper, for several decades art and science had been setting the foundations of uncertainty and distrust in the traditional ways to interpret the world. It is not surprising then that Jewish author Saul Bellow, apparently a writer of "psychological realism" and "the novel of manners," denies all those labeling implications as early as 1959 with the publication of his novel Henderson the Rain King. Readers of this book may easily find out that it is symbolically structured around Joseph Campbell's pattern of the monomyth: Henderson seems to be the typical modernist hero questing for the meaning of life, and in his quest he follows a typical road of trials where he has to undergo different rites of passage. But the novel is more than a worn-out example of modernist psychological realism: it is a huge parody of the modernist belief in the meta-narrative of myth. Henderson is a clear example of a symbol-making animal and being the narrator of his own story, he discloses a life that could be a perfectly exaggerated example for Sigmund Freud to typify the castrated male. Henderson is also an exaggerated example of anthropologist James Frazer's figure of the king who has to die so as to restore life to his land (Frazer XXIV). But Henderson is, above all, a paranoid narrator who reports on how his mental condition improved in his journey to Africa: the story ends when he stops in the symbolic Newfoundland with a little child who cannot talk English and with a little lion cub that represents the spirit of the last god-king of the Wariri tribe: (modernist) symbols that suggest regeneration and the start of a new mythic cycle literally invade the end of this story. However, when he finishes his report Henderson the narrator is still the castrated paranoiac who mentally tries to control the world and his life, but he is bound to get no ultimate answer because, as a human being, Henderson is only able to generate symbols to interpret, but never to know, reality.

In a sense, it could also be argued that Henderson the Rain King is one of the first great contemporary novels to utilize a strategy that many critics associate to postmodern literature: parody. Once the belief in traditional meta-narratives has disappeared, writers may want to go back to traditional styles and strategies in order to criticize them or simply to show that they are also artificially constructed: parody supposes the introduction of an element that produces instability in the realm of the literary traditional. It is, in this sense, a stylistic feature that runs parallel to the new emphasis that science is laying on far-from-equilibrium systems, or what more commonly is referred to as the Theory of Chaos, the second great scientific revolution in our century. 
From an anthropological perspective, chaos theory means the redefinition of the evil meaning the term "chaos" traditionally acquired in western countries. The old mythological dichotomy Chaos vs. Order finds in this set of contemporary scientific theories the end of the predominance and goodness of order for the benefit of a new synthesis where chaos and order are not considered to be opposite but complementary elements. In scientific terms, chaos theory means that now science pays much more attention to probability, randomness, complexity and to all those events and systems that do not seem to follow a fixed pattern. Chaos scientists are interested in local causes, impredictability, bifurcative options and irregularity. In other words, they focus their attention in all those physical gaps that traditional or Newtonian science had systematically tried to ignore. Systematicity and natural laws give way here to the study of small conditions that may generate big reactions, chaotic factors are studied as possible generators of new ordered systems, entropic dissipation is analyzed to see if it will generate negentropic zones. The belief for some of these scientists is that chaos is an order that we cannot understand yet (Gleick), whereas for others, such as Ilya Prigogine, chaos must be studied as a possible generator of new ordered systems.

What is interesting in this revival of the interest for the chaotic aspects of life is not only, as some critics have already pointed out, that chaos theory may be the new meta-narrative that many westerners have been waiting for since the collapsing of traditional grand-narratives: what is especially interesting for cultural and literary criticism is the big coincidences that this new scientific approach shows, with the postmodern condition (Hayles' Introduction). Fragmentation, instability, exemplification and local causes, bifurcation, or the denial of either/or categorical thinking, are all aspects that saturate both contemporary scientific discourse and artistic life. In this sense, there are clear indications that the new ethos proposed by chaos theory and its cultural influence can help critics to explain and define the existence of an apparently paradoxical postmodern realism.

If we have a look at recent criticism on the contemporary American novel, we can come across a number of scholars who substitute the postmodernist in literary grounds for the experimental or metafictional: in this sense postmodernist would qualify the overtly metafictional prose written by novelists like John Barth or Gilbert Sorrentino mostly in the 1970s, a type of fiction that basically represents the late modernist and poststructuralist belief that we cannot escape textuality in our comprehension of reality: that life is a text, as Borges or Nabokov implied, or the fact that we can never escape the symbolic, as Lacan theorized, or that "there is nothing outside the text," as Derrida popularized. But this trend of highly metafictional prose that somehow became the canonized postmodernist text soon gave way to the increasing canonical importance of a different type of text: the socially committed story that reflected the living conditions of marginalized American minorities. For women, African-Americans, Native-Americans, Asian-American, Chicanos, or gays the moment had come to question the traditional values of Anglo-Saxon patriarchy, and American fiction became one more weapon, and at times a very powerful one, in their fight for social justice. A substantial quantity of this type of fiction was written according to realist terms: for political reasons mimesis became all important again, because one of the main aims of writers was to denounce and to be understood by a majority of the reading public. That this type of fiction can be qualified as postmodernist or simply as a socio-literary sequel of postmodernism is rather irrelevant here. But the fact 
seems to be that a big part of the writers that from the 1980s started to become canonical by means of national awards and scholarly recognition looked like realists again and even commented in some interviews that realism was striking back. However, some writers also affirmed that theirs seemed to be a different type of realism, not quite in the style of previous authors (Banks 1995). Some critics, like Heinz Ickstadt or José David Saldívar also suggested the existence of a kind of "Postmodern(ist) Realism." To complicate things more, some other critics coming from the grounds of narratology also commented about the existence of an interesting revival of realist historical novels that were, however, mediated by a certain amount of metafictional strategies: the new fictional trend was named Historiographic Metafiction (Hutcheon). By the 1980s, then, traditional critical definitions were clearly falling down: the limits separating metafiction and realism were not clear any longer (Waugh). Furthermore, other traditional limits were also being questioned by creative writers themselves: the postmodern condition, profit taking, and marketing procedures combined to finally dismantle the frontiers that traditionally seemed to have separated the novel from the short story collection (Kennedy vii-xv). When considering books like Gloria Naylor's The Women of Brewster Place or Russell Banks' Trailerpark it is difficult to decide whether they are novels or short story collections. Traditional realist devices such as a unified narrative voice or one single viewpoint were also giving way to a plurality of angles, to a complexity of lives whose paths somehow met at some moment or place. But this new type of postmodern realism was putting into practice even more perplexing technical strategies such as the use of an unstable narrator who may even question the credibility of the story he or she is telling (Mukherjee's The Holder of the World), or such as the replacement of the protagonist of the story by the importance of place as central motif in the book (this is what happens in the titles by Naylor and Banks above mentioned), or such as the presentation of complementary but opposite endings for the same story, a paradox that obviously supposes again the rejection of the Aristotelian Law of the Excluded Middle. "Excluded middles is bad shit!" one of the characters in Pynchon's The Crying of Lot 49 says as early as 1966, and twenty or thirty years later American novelists still try to convince their readers that middles should not be excluded, that limits are never clear, that narrators cannot be trusted if they are omniscient, and that contemporary writers are being realist in their strategies because their aim is again to reproduce reality as we western people now understand reality.

Clearly the coming back to realist premises meant for writers of this type of postmodern fiction not a necessity to report on the world in mimetic terms but, on the contrary, their recognition that life cannot be easily understood nor depicted from a categorical or merely sensorial perspective. Some examples may help us to recognize the literary effects of this type of realism that has been filtered by postmodernist beliefs. Naylor's The Women of Brewster Place (1982) is not only a perfect example of the dissolution of limits between the novel and the short story collection, as I mentioned earlier, or one more instance of feminist realism and, at times, also of homophobic criticism, as some scholars have suggested. The book is also very effective in producing ontological and narratological confusion. The story textually starts with five pages written in italics, a device that will be repeated at the end of the book to give readers an impression of encapsulation. The events presented in these first and last pages are supposedly narrated by an unknown voice of omniscient powers whose aim is to establish the importance of Brew- 
ster Place as the real protagonist in the book. Then the story unfolds divided in different embedded stories or chapters, almost each one of them dedicated to one female character. The first one tells readers about Mattie Michael, a figure that will reappear in some other episodes and who seems to embody one of the main motifs of the book: the necessity to fight against patriarchy and to stand up for female rights. However, readers are soon informed that Mattie enters a day-dreaming trance that allows us to know many events that befell this character earlier in her life, events that somehow forced her to come to Brewster Place (8). By the end of the last episode, readers are informed that Mattie wakes up and there is no way to know whether she has been only dreaming a strange surrealist event in which the women of Brewster Place have been trying hard to symbolically liberate themselves from patriarchal rule, or whether the whole story in the book has been nothing but a dream. "Dusk," the final italicized section of the book is a parodic evocation of Eliot's The Waste Land. Parody, symbology, different narratorial levels, a multiplicity of perspectives, together with a metafictional use of the narrative voices frame a book that can never claim credibility for its own telling: the reality that The Women of Brewster Place describes is filtered by many doubts and by ontological instability. The only clear boundary that remains at the end of the story is the actual brick wall that separates the African-American women from the rest of the world, Brewster Place from freedom.

New York writer Eric Kraft probably offers in his fiction some of the most interesting examples of American postmodernist realism. Kraft is not only a creative writer but also a person very keen in contemporary physics, and some of his books become persuasive literary attempts to change his readers' traditional views about the world. His stories are always narrated by somebody called Peter Leroy who is very fond of commenting, in the Preface of each book, about the ways in which he-Peter-invents, imagines or remembers the story of his own life! Definitely, Peter Leroy's realist approach differs very much from Daniel Defoe's insistence on credibility. In the Preface of one of Kraft's most popular books, Where Do You Stop (1992), Leroy starts by affirming the difficulties he has to clearly remember things past:

Sometimes my memory seems to be mush, with shining moments scattered through it like chips of marble in wet cement or peas stirred into mashed potatoes. I'd like to take a closer look at some of those moments, but whenever I reach for one I disturb the mush, and the moment I seek sometimes sinks out of sight . . . . Reaching for a chip of marble, I come up with a pea. Once in a while, though, something - some random turbulence in the mush, perhaps - brings to the top a chip that surprises me, one I haven't looked for, but one I'm happy to see.... (1)

In this paragraph, readers may hear echoes coming from modernist writer Marcel Proust but, if they pay a closer attention to this book beginning they may as well discover that it is not simply a highly metaphoric text. It is also a literary transcription of Heisenberg's uncertainty principle, a transcription effected on the reality of the functioning of the human mind: the observer always interferes in the act of observation. Furthermore, this interference may produce an unexpected reaction that could eventually prove very useful for the observer: random turbulence may bring about wonderful results.

The end of the Preface of Where Do You Stop? is equally interesting because Kraft employs it in order to insist on that other motif I mentioned earlier: the blurring of limits between 
the novel and other fictional forms. Among brackets, this is the way Peter Leroy finishes his peculiar Preface:

(By the way: it has been my habit, heretofore, to tell my tale in installments of nearly equal length, the length of novellas. This installment [the book Where Do You Stop?] is the equivalent of three of those. If it actually were three of those, instead of the seamless construction it is, they would have had the titles "Quanto the Minimum," "Ariane's Hip," and "Night Watchman." You may want to look for the boundaries.) (6)

The book is certainly the seamless construction of three different stories that this peculiar metafictional narrator promises in the above paragraph. But readers accepting to play the game suggested at the end of it $\longrightarrow$ to look for the boundaries of the three novellas - are bound to experience big difficulties in order to do so because above all Where Do You Stop? is a novel about the impossibility to find real fixed boundaries in physical reality, something that Eric Kraft demonstrates with the help of contemporary physics to then extrapolate it to the shameful issue of racism: where are the fixed physical limits between being black and being white? Limits - the ones existing between Kraft and Leroy, credibility and imagination, black and white - are where we humans want to establish them, physical reality being nothing but the grounds where fuzziness and turbulence are disguised under a false image of stability.

Very fond of symbols that combine with realist strategies, Indian-born but American author Bharati Mukherjee also offers in her writings an interesting combination of literary devices and scientific beliefs. Probably her most intensively postmodern although realist work up to date is her 1993 novel The Holder of the World, an apparent historical novel that can easily be qualified as a product of historiographic metafiction and that further confirms two relevant issues of the contemporary American novel: the importance of chaos dynamics and poststructuralism, and the inventive role played by the narrator. The Holder of the World is a novel where two parallel stories unfold: one story - the historical one-is a report of the life and adventures of Hannah Easton, born in the colony of Massachusetts in 1670. Hannah is of an early feminist mind and her beliefs will take her to live many adventures in the Coromandel Coast, in India. But the second story is nothing but the parodic quest for knowledge represented in narrator Beigh Master's attempt to narrate Hannah's story. At the back of the narrator's need to create Hannah's story/history stands the indeterminate position of contemporary historiography and the persistent poststructuralist belief in our human incapacity to recreate past events in any accurate or objective way. Very soon in her report narrator Beigh Masters discloses her poststructural and chaotic stance to recreate the past: she participated in a seminar on American Puritans at Yale and,

that seminar set in motion a hunger for connectness, a belief that with sufficient passion and intelligence we can deconstruct the barriers of time and geography. Maybe that led, circuitously, to [her boyfriend] Venn. And to the Salem Bibi [Hanna Easton] and the tangled lines of India and New England. (11)

Connectness is a key issue in chaos theory (see, for instance, Prigogine's understanding of complex dynamics): a new order can be created out of fragmented, unconnected elements, and that is precisely what Beigh Masters's task is going to be in the book. Hannah Easton's seventeenth-century story unfolds as the result of its narrator's activity as a new historicist, an arche- 
ologist of knowledge who also shows in her report interesting Derridean traces. Puritan Massachusetts and Mughal India offers the writer the possibility to deconstruct traditional binarism. In her narrator's words there is also an early anticipation or "manifesto" that sets the grounds for the battle between binarist patriarchy and the archeologist's literary imagination:

I move from unfurbished room to room, slaloming between us and them, imagining our wonder and their dread, now as a freebooter from colonial Rehobot or Marblehead, and now as a Hindu king or Mughal emperor watching the dawn of a dreadful future through the bloody prism of a single perfect ruby, through an earring or a jewel from the heavy necklace. (13; the author's emphasis)

The narrator uses her imagination to re-present the story of Hannah Easton, and her representation becomes a discursive attempt to eradicate some of the most powerful binarisms of traditional patriarchal thinking: man/woman, white/colored, town/forest, I/Other. In a parodic way of cyberpunk reminiscences, the narrator's boyfriend Venn also becomes her assistant and develops a virtual-reality program that Beigh uses to technologically travel back to the past of Hannah's life.

In the narrator's invented story realist descriptions abound, historical documents are presented, real personages appear: realism is certainly back but readers may easily conclude that, as corresponds to the postmodern times of its production, Mukherjee's The Holder of the World is a novel where the question of "what is happening in reality?" gives way to the importance of "how is reality being reported?" The shift from the what to the how obviously represents one of the big cultural changes that the postmodern condition brought about, and a final example will suffice, I hope, to suggest that the "telling" of the story has become a very important device in contemporary realist fiction.

Tim O'Brien is a Vietnam veteran who has written a number of books where limits between the novel and the short story are also blurred, as blurred are the limits between factuality and invention. Is O'Brien actually remembering real events of the Vietnam war? and are his representations of those events truly "objective"? These two questions could be typically formulated by people interested in the strategies of classic realism, but anticipating them O'Brien wrote a celebrated short story that he first published in Esquire and then in his novel or collection of short stories The Things They Carried (1990), a book that is simply labeled as "a work of fiction." The short story I am referring to is called "How To Tell a True War Story," a title that seems to imply a literary manifesto of sorts. And that is what the story eventually proves to be: the story may be only one and based on a real event, but the ways to tell it are many, or at least some. "This is true," O'Brien writes at the beginning of his story. "It's all exactly true," he continues later on. But what is true is never clear for his readers: different and contradictory versions of the same story are presented by O'Brien's narrator, a voice that maintains that "truths are contradictory" (87), or that

[to] generalize about war is like generalizing about peace. Almost everything is true. Almost nothing is true. ... You feel an intense, out-of-the-skin awareness of your living self-your truest self, the human being you want to be and then become by the force of wanting it. (87)

But then, before readers may start believing in the existence of a "truest self," the narrator insists: "That's a true story that never happened" (90). 
Nowadays it is clear that the human understanding of reality has been strongly modified from the times of classic nineteenth-century realism: both science and creative realist writers are systematically telling us that reality, whatever it is, is beyond our capacity to fully recognize it, and that as it stands now, it is an enigmatic ground where the impredictable, the irregular, the complex, or the indeterminate are in a continual process of replacing, also in the grounds of culture, the traditional limits of categorical and Newtonian interpretation. The poststructuralist notion that presents life as a text has gradually modified our focus of argumentation: what is the world has been replaced by how is the world interpreted and reported by different people. And so postmodern realism becomes a way to analyze how we, unstable subjects, interpret the world at present, far away from universal values and truths; and the story has become the story of the telling of a story, in realist terms, whatever realist may mean for you or for me.

\section{WORKS CITED}

Banks, Russell. "Back to Realist Grounds: An Interview with Russell Banks,"by Francisco Collado Rodríguez. Revista de Estudios Norteamericanos 4 (1995): 89-98. Trailerpark. New York: Ballantine, 1981.

Campbell, Joseph. The Hero With a Thousand Faces. [1949] Princeton: PUP, 1968.

Collado-Rodríguez, Francisco. "Trespassing Limits: Pynchon's Irony and the Law of the Excluded Middle," Oklahoma City University Law Review 24 (1999). (Forthcoming.)

Daiches, David. A Critical History of English Literature. Vol 3 The Restoration to 1900. London: Secker \& Warburg, 1960.

Davies, Paul. The Cosmic Blueprint. Harmondsworth: Penguin, 1987.

Davies, Paul, and John Gribbin. The Matter Myth: Beyond Chaos and Complexity. Harmondsworth: Penguin, 1991.

Frazer, James G.. The Golden Bough: A Study in Magic and Religion. London: Macmillan, 1922.

Gleick, James. Chaos: Making a New Science. New York: Viking, 1987.

Hayles, N. Katherine. How We Became Posthuman: Virtual Bodies in Cybernetics, Literature, and Informatics. Chicago: The U of Chicago P, 1999.

Hayles, N. Katherine, ed. Chaos and Order: Complex Dynamics in Literature and Science. Chicago: The U of Chicago P, 1991.

Hutcheon, Linda. A Poetics of Postmodernism: History, Theory, Fiction. New York: Routledge, 1988. 
Ickstadt, Heinz. "Contemporary American Novel: Between Post-Modernism and NeoRealism." Actas del XII Congreso Nacional de AEDEAN. Alicante: Universidad de Alicante, 1988: 99-109.

Kennedy, J. Gerald. "The American Short Story Sequence—Definitions and Implications." Modern American Short Story Sequences. Ed. J. Gerald Kennedy. Cambridge: CUP, 1995.

Kraft, Eric. Where Do You Stop? New York: Crown, 1992.

McHale, Brian. Postmodernist Fiction. London: Methuen, 1987.

Manganaro, Marc. Myth, Rhetoric, and the Voice of Authority. New Haven \& London: Yale UP, 1992.

Mukherjee, Bharati. The Holder of the World. New York: Knopf, 1993.

Nadeau, Robert. Readings from the New Book on Nature: Physics and Metaphysics in the Modern Novel. Amherst: The U of Massachusetts P, 1981.

Naylor, Gloria. The Women of Brewster Place. London: Minerva, 1982.

O'Brien, Tim. The Things They Carried. Harmondsworth: Penguin, 1990.

Prigogine, Ilya, and Isabelle Stengers. Order Out of Chaos: Man's New Dialogue with Nature. London: Flamingo, 1985.

Saldívar, José David. "Postmodern Realism." The Columbia History of the American Novel. Ed. Emory Elliott. New York: Columbia UP, 1991: 521-541.

Watson, George. The Strory of the Novel. London: Macmillan, 1979.

Waugh, Patricia. Metafiction: The Theory and Practice of Self-Conscious Fiction. London: Methuen, 1984.

White, Eric Charles. "Contemporary Cosmology and Narrative Theory." Literature and Science: Theory \& Practice. Ed. Stuart Peterfreund. Boston: Northeastern UP, 1990: 91-111.

Wilson, Edmund. Axel's Castle. New York: Scribner's, 1931. 